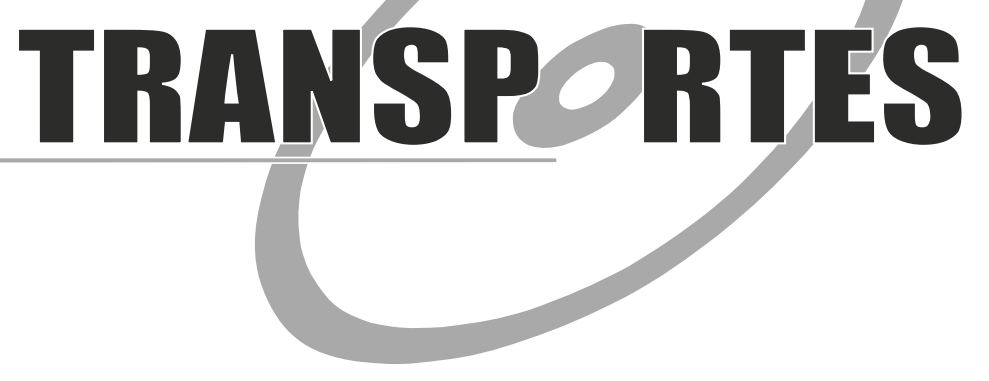
A Revista Transportes ISNN 22371346 (online) é publicada pela Associação Nacional de
Pesquisa e Ensino em Transportes

\author{
Editor \\ José Reynaldo Anselmo Setti, EESC-USP \\ Conselho Editorial \\ Antônio Galvão Novaes, UFSC, Brasil \\ Antônio Nélson Rodrigues da Silva, EESC-USP, Brasil \\ Orlando Strambi, EP-USP, Brasil \\ Maria Alice Prudêncio Jacques, UnB, Brasil \\ Luis Antonio Lindau, UFRGS, Brasil \\ Liedi Bariani Bernucci, EP-USP, Brasil \\ Licinio da Silva Portugal, COPPE-UFRJ, Brasil \\ Jose Manuel Viegas, IST, Portugal \\ José Eugênio Leal, PUC-Rio, Brasil \\ Carlos David Nassi, COPPE-UFRJ, Brasil \\ Claudio Barbieri da Cunha, EP-USP, Brasil \\ Carlos Felipe Grangeiro Loureiro, UFC, Brasil \\ Vânia Barcellos Gouvea Campos, IME, Brasil \\ Werner Kraus Junior, UFSC, Brasil \\ Secretaria Geral \\ Thereza Maria Afflalo

\section{Produção Editorial} \\ André Cunha, EESC - USP \\ Jose Elievam Bessa Junior, EESC-USP \\ Bruno Vieira Bertoncini, UFC

\section{Endereço} \\ Revista Transportes/ANPET \\ Caixa Postal 68512 \\ 21941-972 - Rio de Janeiro - RJ \\ E-mail: secretaria_anpet@anpet.org.br \\ Telefone: (21) 2562 - 8179 \\ Fax: (21) 2562 - 8727 \\ Home Page: \\ www.revistatransportes.org.br
}

O conteúdo dos artigos publicados é de responsabilidade dos respectivos autores, não expressando, necessariamente, a opinião do Conselho Editorial. 